
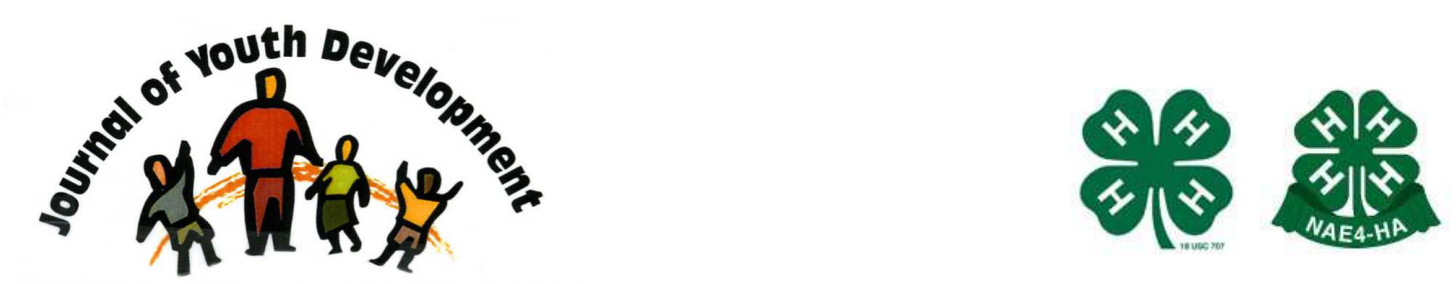

Bridging Research \& Practice

\title{
The Youth Empowered for Success Program: A Multi-faceted Approach to Youth Leadership Development and School Culture Change in Southern Arizona
}

\author{
Pam Parrish \\ Community Partnership of Southern Arizona \\ Tucson, AZ \\ Pam.parrish@cpsa-rbha.org \\ Mari Wilhelm \\ University of Arizona \\ Tucson, AZ \\ wilhelmm@ag.arizona.edu \\ Yvette Florez-Urcadez \\ University of Arizona \\ Tucson, AZ \\ florez@email.arizona.edu \\ Daniel A. Jeffrey \\ University of Arizona \\ Tucson, AZ \\ djeffrey@email.arizona.edu \\ James Roebuck \\ University of Arizona \\ Tucson, AZ \\ roebuck@email.arizona.edu \\ Bill B. Burnett \\ Community Partnership of Southern Arizona \\ Tucson, AZ \\ Bill.burnett@cpsa-rbha.org
}




\title{
JOURNAL OF YOUTH DEVELOPMENT \\ bridging research and practice

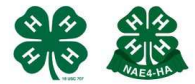

Volume 3, Number 2, Fall 2008

Article 080302PA003

\section{The Youth Empowered for Success Program: A Multi-faceted Approach to Youth Leadership Development and School Culture Change in Southern Arizona}

\author{
Pam Parrish and Bill B. Burnett \\ Community Partnership of Southern Arizona \\ Mari Wilhelm, Yvette Florez-Urcadez, Daniel A. Jeffrey and James Roebuck \\ University of Arizona
}

\begin{abstract}
Arizona's first Teen Institute (TI) program, Youth
Empowered for Success, began in July 2004. It is the first TI-based project to focus on nurturing resilience via Health Realization (Pransky, 2007). The YES program's design to "create conditions for success" in high schools is discussed. YES utilizes a strengths-based, multi-faceted approach of (1) teaching participants how to access their innate resilience and common sense (Health Realization), (2) training them in community development for school culture change and (3) helping them develop meaningful partnerships with adults. YES also expands upon the TI model by providing staff support for community development throughout the academic year. It is hypothesized that these efforts ultimately will increase overall well-being and reduce the incidence of alcohol, tobacco and other drug use (ATOD) as well as depression and suicide among youth.
\end{abstract}

\section{Introduction}

Teen Institutes (TIs) have been demonstrated to be an effective approach to both developing youth leadership and preventing substance abuse among participants (National Association of Teen Institutes, 2007). The TI model, which began in Ohio in 1965, now includes more than 50 TIs offered in 21 states (Nation Association of Teen Institutes, 2007). 
Arizona's first TI program, Youth Empowered for Success, began in July 2004. YES is designed to empower high-school youth to become leaders capable of creating "conditions for success" within their schools. YES comprises two primary components: Teen Institute and the SchoolBased Cultural Change program.

The project is a collaborative effort developed and sponsored by the Community Partnership of Southern Arizona (CPSA), with funding from the Substance Abuse and Mental Health Services Administration through the Arizona Department of Health Services. CPSA contracts with several agencies to provide direct service for the project.

YES has developed a comprehensive approach of drawing out participants' innate resilience while training them in community development for school culture change and helping them develop meaningful partnerships with adults. Group learning about innate resilience, via Health Realization, forms the core of each summer's week-long YES Teen Institute, which is attended by youth-adult teams from participating schools. Then YES provides ongoing staff support throughout the academic year. The YES teams develop and implement school-wide strategic plans to address conditions that may interfere with students' bonding to school. At the same time, team members reinforce and share their learning about Health Realization via discussion and processing of experiences.

As teams' efforts have a positive impact on conditions within the schools, it is anticipated that school bonding and commitment will increase among students. School bonding, or connectedness, has been shown to help prevent substance abuse and a variety of other negative behaviors, as well as being protective against depression and suicide (Bosworth, 2000).

The focus on accessing resilience via Health Realization is unique to YES. Historically, TIs have provided information on drugs and problem behaviors and training in prevention strategies without an explicit philosophical framework.

As of the 2006-07 academic year, 25 high schools in Southeastern Arizona have established active YES Teams. Schools participating in YES range from urban and suburban facilities with more than 2,000 students to rural schools with fewer than 60. YES Teams are found on the Tohono O'odham and San Carlos Apache tribal nations and in historically Mormon or MexicanAmerican communities, as well as in Arizona's second largest metropolitan area, Tucson.

\section{Resilience, Health Realization and Youth Development}

YES is built upon resilience research, using three strategies:

- Health Realization

- Youth-Adult Partnerships and

- Community Development

A large body of research has demonstrated the relationship between resilience/protective factors and youth behavior (Benard, 2004; Hawkins, Catalano, \& Miller, 1992; Scales \& Leffert, 1999; Werner \& Smith, 1992). Health Realization was selected as YES' philosophical base and vehicle for personal change after a review of the literature describing research-based programs known to support resilience. The Substance Abuse and Mental Health Services' Center for Mental Health Services suggests that Health Realization is a flexible approach appropriate both 
for individuals and groups (Davis, 1999). Health Realization also is implemented via the community psychology model, in which a small group of committed leaders spreads the understanding to its peer group, an approach consistent with the YES' design.

\section{Health Realization}

Health Realization is based on three assumptions concerning the nature of human psychological functioning (Kelley, 2004):

- Thought is the source of human experience.

- Regardless of their current state, all people have the innate capacity for healthy psychological functioning.

- There are two modes of thought, one related to memory and the other to healthy, common-sense, wiser intelligence.

Health Realization holds that "as understanding [of these principles] increases, the youth naturally become more hopeful and resilient even during difficult times and insecure moods" (Mills, 1997).

\section{Youth-Adult Partnerships}

YES incorporates Youth-Adult Partnerships (Y-APs) in both the learning and community development components - as well as in the overall program design. Research provides evidence that youth benefit from such partnerships, and Y-APs offer a viable strategy for community development and fostering social change Camino, 2000a; Camino, 2000b; Camino \& Zeldin, 2002). Research also suggests that Y-APs where youth are involved in decision-making contribute to protective factors that help young people "achieve mastery, compassion, and health" (Shepard et. al., 2000).

\section{Community Development}

The third part of YES' foundation, community development to address school culture and conditions, is an adaptation of the Youth Opportunity Planning Process (Lofquist, 1990) and BreakAway (Lynn \& Lofquist, 2002). This component of YES was crafted in consultation with "BreakAway" author/developer David D. Lynn. Y-APs are intrinsic to this process, which provides a flexible framework for youth to make an impact on their school community. Meaningful participation such as this is an important factor contributing to youth resiliency (Benard, 2004).

Proponents of all these approaches and strategies share a belief that youth have innate resilience and wisdom and are valuable resources, with the capacity to make a positive impact in their communities. The YES program incorporates this belief into its overall framework and each of its program components.

\section{YES Teen Institute}

The first YES Teen Institute (YES/TI) was held in 2004 at the University of Arizona, attracting 86 youth and adults from 15 high schools throughout Southeastern Arizona. Since then, YES/TI has been held annually on college and university campuses and has grown to approximately 100 youth from 25 high schools. The number of CPSA-funded staff at YES/TI grew from more than 20 at the first event to almost 30 in 2006. CPSA-funded staff were supplemented by members of the Arizona National Guard's Drug Demand Reduction Team, the Cochise County 
Juvenile Justice System, and individual schools. In addition, adult and youth alumni serve as volunteer staff at YES/TI.

Subjects, in teams of at least 4 students and one staff member and parent from each school, participate in the week-long YES/TI over the summer. Youth are selected with input from school staff and other students to represent diverse social groups within the school. Each youth and adult participates in three different groups at YES/TI:

- Learning Groups, in which they explore the principles of Health Realization;

- Family Groups, in which they receive emotional support and process lessons and insights from the week; and

- School Teams, in which they learn skills for community development.

Each of these groups meets daily, allowing participants to interact in a positive, structured way with youth and adults from a wide variety of backgrounds and experiences.

All participants attend Community Meetings with inspirational speakers each morning of YES/TI. Daily Learning Groups use an experiential approach to convey understanding of Health Realization principles, from a curriculum developed by YES in consultation with author/practitioner Jack Pransky, Ph.D. Adults and youth meet separately in daily Family Groups of about 10 participants. The remainder of the week is filled with structured recreational activities and social events. On the last day, a closing Community Meeting is held that includes a slide-show and video (produced by a separate team of students from a local high school) of the week's activities.

Most activities are led by Youth Mentors who are YES/TI alumni selected by their peers as role models and leaders. These Youth Mentors help plan and provide input into the design of YES/TI each year. Youth Mentors who graduate from high school and adult alumni of YES/TI also may become volunteer or stipened staff at YES/TI and/or in the School-Based Cultural Change component.

\section{The School-Based Cultural Change Program}

School-Based Cultural Change using community development is the second component of the YES project.

Upon returning to school after YES/TI, the youth-adult YES Teams plan and conduct (with YES staff support) a school-wide process to identify areas of concern to students, administrators and faculty. They then recruit other youth and adults, including those from social groups not already represented, to join the team for action planning and implementation of strategies to address identified issues and conditions. Each school team receives a small stipend to fund activities and work towards achieving a "quick success," a small, achievable objective that helps build confidence as they progress towards their goal. Additional action planning is conducted as needed during the year.

Throughout the process, YES Teams receive support from YES staff called "coaches," who weave in reminders of Health Realization and ensure the teams process lessons learned from their projects. Though most team projects focus on issues such as breaking down barriers among social groups, abstaining from drug use and staying in school, their true value is in bringing together youth from disparate social groups on projects that benefit all students. 
Most YES Teams meet weekly. In January, teams from all 25 schools come together for a 4hour Health Realization refresher, sharing of project successes and celebration of their progress.

\section{Program Eligibility}

High schools are eligible to participate in YES for as long as YES coincides with their principals' top five priorities. This is ascertained by completion of an annual Letter of Agreement with each principal and by ongoing communication between school administration and YES staff. Youth participants for YES/TI are chosen by YES staff in consultation with youth and adults at the schools, based on their natural leadership abilities and their representation of various social groups. Any interested youth in a participating school may join YES' School-Based Cultural Change component. Adult participants are chosen based on their commitment to working as partners with youth, their positive attitude, their leadership qualities, and commitment to working with the team for at least the upcoming school year.

Youth may continue to participate in YES as team members and/or Youth Mentors throughout high school, and as Youth Mentors after graduation. Youth Mentors - youth who have attended previous YES/TIs, have continued their involvement with the program over one or more years and have been selected as mentors by their peers - play an important role in planning and implementing all YES events. They receive additional training in Health Realization and group facilitation skills; help facilitate Learning Groups and other activities at YES/TI; and help plan and act as emcees at YES/TI and the annual Celebration.

\section{Program Evaluation}

Jaycox et al. (2006) assert that youth development and substance-abuse prevention programs are beginning to recognize a need for flexibility in effective evaluation design and implementation. The YES program evaluation has been conducted every year and has evolved along with the program, with promising results.

\section{Evaluation design}

Survey measures were selected or developed collaboratively by the evaluation team and program developers from CPSA. Surveys were designed to assess the perceived impact of YES activities on a variety of constructs associated with Protective Factors, including resilience, selfefficacy, planning skills, knowledge of Health Realization, emotional well-being and perceptions of positive school climate and drug-use risks and norms. The last two constructs were measured using CSAP-recommended Core Measures.

It was determined that a mix of pre/post and retrospective surveys would best balance the challenges of survey administration with the need to assess program outcomes. A retrospective pre-test design was adopted for several reasons:

1. Youth could reflect on key concepts after obtaining basic knowledge of the subjects

2. It is less disruptive to school and learning environments where time and resources are factors

3. It provides results comparable to traditional methods (Pratt, McGuigan \& Katzev, 2000). 
Table 1

YES evaluation implemented in 2006-07

\begin{tabular}{|c|c|c|}
\hline Group surveyed & Dates surveyed & $\begin{array}{l}\text { Scales used in } \\
\text { outcome analysis }\end{array}$ \\
\hline $\begin{array}{l}\text { "Core Team" (YES/TI } \\
\text { participants) } \\
\mathrm{N}=47^{\wedge}\end{array}$ & $\begin{array}{l}\text { July } 2006 \\
\text { April/May } 2007\end{array}$ & 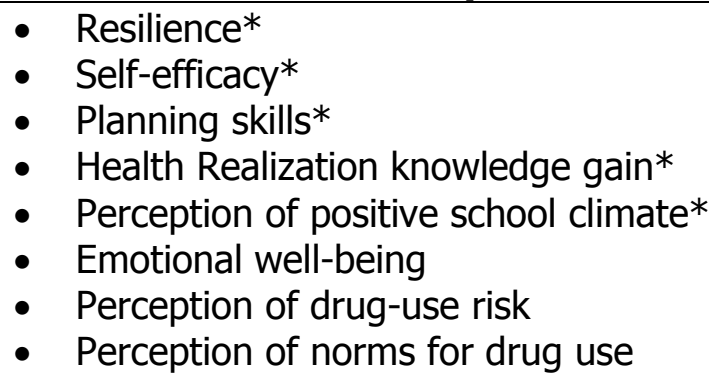 \\
\hline $\begin{array}{l}\text { "Action Team" } \\
\text { (Joined in August } \\
2006 \text { or later) } \\
\mathrm{N}=52\end{array}$ & April/May 2007 & $\begin{array}{ll}\text { - } & \text { Resilience* } \\
\text { - } & \text { Self-efficacy* } \\
\text { - } & \text { Planning skills* } \\
\text { - } & \text { Health Realization knowledge gain* } \\
\text { - } & \text { Perception of positive school climate* }\end{array}$ \\
\hline
\end{tabular}

$\wedge$ Number of matched surveys * $\quad *$ retrospective pre-test used

Retrospective data were collected from YES Team members who participated in the Teen Institute ("Core Team") in July 2006, at the end of YES/TI, and also in April/May 2007. Participants were asked to think back "before" YES/TI to answer the retrospective questions, and then to answer based on their feelings "today." "Before" answers were used as a baseline to analyze change over time. An identical format was used for the April/May wave of data collection, with "today" answers used for comparison. The same approach was not appropriate with the scales for emotional well-being and perceptions of drug-use risk and norms because they already ask the participant to think back over the previous 30 days. Data for those scales were obtained by comparing standard pre-test answers collected after YES/TI to post-test answers obtained in April/May 2007.

Youth who joined YES during the school year ("Action Team") were surveyed in April/May 2007 only. To answer the retrospective items, participants were asked to think back "before" their involvement in YES activities, and then to answer based on their feelings "today." Scales that could not be administered this way (emotional well-being and perceptions of drug-use risk and norms) were not used to evaluate the Action Team's outcomes.

\section{Results}

Change over time for the YES Core Team reached statistical significance for resilience, selfefficacy, planning skills, knowledge of Health Realization, perception of positive school climate and perception of drug-use risks. Non-significant changes were seen on other scales, which were relatively high at pre-test. Outcome results for the Core Team are shown in the table below. A 4-point Likert scale was used. 
Table 2

YES Core Team outcomes, 2006-07

\begin{tabular}{|l|c|c|c|c|c|c|}
\hline \multicolumn{1}{|c|}{ Scale/construct } & $\mathbf{N}$ & $\begin{array}{c}\text { July } \\
\mathbf{2 0 0 6}\end{array}$ & $\begin{array}{c}\text { April/ } \\
\text { May } \\
\mathbf{2 0 0 7}\end{array}$ & $\begin{array}{c}\text { Mean } \\
\text { change }\end{array}$ & $\begin{array}{c}\text { Mean } \\
\text { \% } \\
\text { change }\end{array}$ & $\begin{array}{c}\text { Significance } \\
\text { (2-tailed) }\end{array}$ \\
\hline Resilience & 44 & 3.30 & 3.67 & 0.37 & 11.27 & 0.000 \\
\hline Self-efficacy & 46 & 2.96 & 3.35 & 0.39 & 13.37 & 0.000 \\
\hline Planning skills & 43 & 2.89 & 3.44 & 0.55 & 19.04 & 0.000 \\
\hline $\begin{array}{l}\text { Knowledge of Health } \\
\text { Realization }\end{array}$ & 43 & 2.92 & 3.47 & 0.55 & 18.67 & 0.000 \\
\hline Emotional well-being & 46 & 3.58 & 3.45 & -0.13 & -3.55 & 0.215 \\
\hline $\begin{array}{l}\text { Perception of positive } \\
\text { school climate }\end{array}$ & 43 & 2.67 & 2.88 & 0.21 & 7.88 & 0.009 \\
\hline $\begin{array}{l}\text { Perception of drug- } \\
\text { use risks }\end{array}$ & 46 & 3.53 & 3.64 & 0.11 & 3.12 & 0.044 \\
\hline $\begin{array}{l}\text { Perception of norms } \\
\text { for drug use }\end{array}$ & 46 & 3.72 & 3.64 & -0.08 & -2.19 & 0.137 \\
\hline
\end{tabular}

Note: $\mathrm{p} \leq .05$

The Action Team also reported significant positive change in all constructs that were measured, via the retrospective pre-test and post-test. Results are shown below, again based on a 4-point Likert scale.

Table 3

YES Action Team outcomes, 2006-07

\begin{tabular}{|l|c|c|c|c|c|c|}
\hline \multicolumn{1}{|c|}{$\begin{array}{c}\text { Scale/ } \\
\text { construct }\end{array}$} & $\mathbf{N}$ & $\begin{array}{c}\text { "Before" } \\
\text { mean }\end{array}$ & $\begin{array}{c}\text { "Today" } \\
\text { mean }\end{array}$ & $\begin{array}{c}\text { Mean } \\
\text { change }\end{array}$ & $\begin{array}{c}\text { Mean \% } \\
\text { change }\end{array}$ & $\begin{array}{c}\text { Significance } \\
\text { (2-tailed) }\end{array}$ \\
\hline Resilience & 44 & 3.36 & 3.60 & 0.24 & 7.17 & 0.00 \\
\hline Self-efficacy & 48 & 2.90 & 3.11 & 0.21 & 7.28 & 0.00 \\
\hline Planning skills & 48 & 3.05 & 3.48 & 0.43 & 14.13 & 0.00 \\
\hline $\begin{array}{l}\text { Knowledge of } \\
\text { Health Realization }\end{array}$ & 48 & 2.98 & 3.41 & 0.43 & 14.13 & 0.00 \\
\hline $\begin{array}{l}\text { Perception of } \\
\text { positive school } \\
\text { climate }\end{array}$ & 44 & 2.64 & 2.84 & 0.20 & 7.70 & 0.00 \\
\hline
\end{tabular}

Note: $p \leq .05$

\section{Conclusions}

Overall, the data suggest the YES program has a positive effect upon its participants, especially in the areas of Health Realization knowledge and planning skills. The school-based cultural change component of the YES project remains to be evaluated. 


\section{YES: Present and Future}

Through the YES program, prevention-themed messages can reach many youth, as important life skills are developed. In addition, YES' addition of Health Realization to the Teen Institute model and its focus on changing conditions in the schools, rather than merely starting new programs, increases the likelihood of sustained individual and system change with impacts that will affect all students in participating high schools now and into the future. As students' efforts have a positive impact on conditions within the schools, it is anticipated that bonding and commitment will increase among students. School bonding, or connectedness, has been shown to help prevent substance abuse and a variety of other negative behaviors, as well as being protective against depression and suicide (Bosworth, 2000).

CPSA and its partners currently are compiling an implementation manual for YES as a basis for future replication. Ultimately, CPSA plans to pursue YES' inclusion in the National Registry of Evidence-Based Programs and Practices.

In sum, Youth Empowered for Success has developed a promising, comprehensive approach built upon a belief in every participant's innate resilience and common sense. Based on lessons learned from evaluation, we hope to refine the YES project while maintaining its core philosophy and emphasis on nurturing individual strengths and capacities while providing tools to create conditions for success in high schools.

\section{References}

Benard, B. (2004). Resiliency: What we have learned. San Francisco: WestEd.

Bosworth, K. (2000). Protective schools: Linking drug abuse prevention with student success. Tucson: University of Arizona Regents.

Camino, L. (2000a). Putting youth-adult partnerships to work for community change: Lessons from volunteers across the country. Community Youth Development Journal, 1, 27-30.

Camino, L. (2000b). Youth-adult partnerships: New territory in community work and research. Applied Developmental Science, 4, 11-20.

Camino, L., \& Zeldin, S. (2002). Making the transition to community youth development: Emerging roles and competencies for youth- serving organizations and youth workers. In T. Burke, S.P. Curnan, J. Erickson, D.M. Hughes, N. Leon, R. Liem, K.J. Pittman, J. Terry, \& D. Woonteiler (Eds.), Community Youth Development Anthology. Sudbury, MA: Institute for Just Communities, Brandeis University.

Davis, N.J. (1999). School violence prevention: Status of research-based programs: Researchbased programs that foster resilience: A general approach applied in different settings. Working paper retrieved April 23, 2002, from http://mentalhealth.samhsa.gov/schoolviolence/part2chp2.asp 
Hawkins, J.D., Catalano, R.F., \& Millar, J.Y. (1992). Risk and protective factors for alcohol and other drug problems. Psychological Bulletin, 112(1), 64-105.

Jaycox, L.H., McCaffrey, D.F., Ocampo, B.W., Shelley, G.A., Blake, S.M., Peterson, D.J., et al. (2006). Challenges in the Evaluation and Implementation of School-based Prevention and Intervention Programs on Sensitive Topics. American Journal of Evaluation, 27(3), 320-336.

Kelley, T.M. (Summer, 2004). Positive psychology and adolescent mental health: False promise or true breakthrough? Adolescence, $39(154)$, 257-277.

Lofquist, W.A. (1990). The Youth opportunity planning process: A Systematic approach to involving community groups in strategic planning. Tucson: Associates for Youth Development.

Lynn, D.D., \& Lofquist, W.A. (2002). BreakAway: A Framework for Creating Positive School Communities. Tucson: Development Publications.

Mills, R.C. (1997). Psychology of mind-health realization: Summary of clinical, prevention, and community empowerment applications documented outcomes, unpublished paper. Retrieved February 1, 2007, from http://mentalhealth.samhsa.gov/schoolviolence/part2chp2.asp.

National Association of Teen Institutes website. Retrieved February 2, 2007, from www.teeninstitute.org

Pransky, J. (2007). Personal communication, December 7, 2007.

Pratt, C.C., McGuigan, W.M., \& Katzev, A.R. (2000). Measuring program outcomes: Using retrospective methodology. The American Journal of Evaluation, 21(3), 341-349.

Scales, P.C., \& Leffert, N. (1999). Developmental assets: A synthesis of the scientific research on adolescent development. Minneapolis: Search Institute.

Shepard, Z., McDaniel, A.K., Topoitzes, D., \& Calvert, M. (2000). Youth in decision-making: $A$ study on the impacts of youth on adults and organizations. National 4-H Council: Madison WI.

Werner, E.E. \& Smith, R.S. (1992). Overcoming the odds: High-risk children from birth to adulthood. Ithaca: Cornell University.

(C) Copyright of Journal of Youth Development Bridging Research and Practice. Content may not be copied or emailed to multiple sites or posted to a listserv without copyright holder's express written permission. Contact Editor at: patricia.dawson@oregonstate.edu for details. However, users may print, download or email articles for individual use.

ISSN 2325-4009 (Print); ISSN 2325-4017 (Online) 